\title{
Terapia génica contra la insensibilidad congénita al dolor con anhidrosis.
}

\author{
María Mercedes Alcón Calderón, Alvaro Antolínez Fernández, Cristina García Fernándeza \\ Departamento de Biología de Sistemas, Facultad de Medicina, Universidad de Alcalá (UAH). Alcalá de Henares \\ (Madrid). \\ a. andrecris19971997@gmail.com \\ V Congreso de Señalización Celular, SECUAH 2020. \\ 16-18 de marzo, 2020. Universidad de Alcalá. Alcalá de Henares, Madrid. España.
}

Palabras clave: CIPA; TrkA: nociceptores; NTRK1

\section{Resumen}

La insensibilidad congénita al dolor es una condición congénita rara, siendo el tipo IV de la enfermedad, que además presenta anhidrosis, el más frecuente entre la población y para el cual actualmente no existe tratamiento y los estudios al respecto son puramente teóricos. En este trabajo teórico proponemos el estudio molecular de la enfermedad para permitir el desarrollo de terapias encaminadas a solventar el problema. Para ello, estudiamos el gen NTRK1, gen codificante del receptor tirosina quinasa TrkA, que actúa como regulador de la diferenciación de neuronas sensoriales y que en este caso, se encuentra mutado. El estudio de esta mutación y sus consecuencias se realizó mediante ensayos de secuenciación y genotipado de individuos, así como también se propuso una terapia génica con CRISPR/Cas9 en modelos in vivo y diversos ensayos in vitro mediante western-blot y citometría de flujo. Nuestros resultados muestran la posibilidad de diseñar un diagnóstico de portadores y de aplicar la terapia génica con el fin de revertir la mutación del gen y conseguir el correcto funcionamiento de las neuronas. La existencia de conocimiento teórico sobre la enfermedad y la posibilidad del diseño de terapias posibles para ella constituyen un paso previo para investigar las causas y consecuencias funcionales de la misma.

Cita: Alcón Calderón, María Mercedes; Antolínez Fernández, Alvaro; García Fernández, Cristina (2020) Terapia génica contra la insensibilidad congénita al dolor con anhidrosis. Actas del V Congreso de Señalización Celular, SECUAH 2020. 16-18 de marzo, 2020. Universidad de Alcalá. Alcalá de Henares, Madrid. España. dianas 9 (1): e202003fa04. ISSN 1886-8746 (electronic) journal.dianas.e202003fa04 http://www3.uah.es/dianas?e202003fa04. URI http://hdl.handle.net/10017/15181

Copyright: (c) Alcón-Calderón MM, Antolínez-Fernández A, García-Fernández C. Algunos derechos reservados. Este es un artículo open-access distribuido bajo los términos de una licencia de Creative Commons Reconocimiento-NoComercial-SinObraDerivada 4.0 Internacional. http://creativecommons.org/licenses/by-nc$\mathrm{nd} / 4.0 /$

\section{Introducción}

La insensibilidad congénita al dolor, denominada también como neuropatía hereditaria sensorial y autonómica, es una enfermedad hereditaria poco frecuente que se caracteriza por una disfunción sensorial y autonómica en la que se produce una insensibilidad al dolor. Fue descrita por primera vez en 1932, donde se pensaba que la causaban fallos en el sistema nervioso central [1]. Sin embargo, en la actualidad se cree que esta más relacionada con mutaciones en diversos genes. Por lo que según los errores genéticos se pueden dar 5 tipos diferentes a día de hoy en la que la expresión fenotípica es variable: el tipo I se caracteriza por ser la única de herencia autosómica dominante y en ella se produce una pérdida progresiva de la sensación de dolor y de la temperatura, en el tipo II se produce una alteración del tacto y de la sensibilidad a la presión, además de variaciones en la insensibilidad al dolor, el tipo III afecta a la percepción del dolor y de la temperatura, el tipo IV presenta una insensibilidad a los estímulos dolorosos y ausencia de sudoración y el tipo $\mathrm{V}$, similar al IV con la diferencia de que la producción de sudor es parcial [2].

En el presente trabajo estudiaremos el tipo IV, también denominado CIPA, ya que es el tipo más frecuente de la enfermedad [3]. Al tratarse de una enfermedad autosómica recesiva se necesita que ambas copias del gen en la célula estén mutadas, lo que caracteriza a estas personas a tener incapacidad para percibir dolor o temperatura [4,5], y a tener una sudoración ausente debido al atrofio de las glándulas sudoríparas.

La CIPA es extremadamente rara. Principalmente los países más afectados por esta enfermedad son Estados Unidos con sólo 100 casos documentados y Japón con más de 300 debido a que la enfermedad es más recurrente en poblaciones genéticamente homogéneas [6].

Desde el punto de vista molecular, la enfermedad se caracteriza por mutaciones en el gen NTRK1 que conlleva una alteración en el receptor TrkA al que codifica [7]. Este receptor está implicado en la supervivencia de células nerviosas, en la diferenciación de nociceptores e interviene en el procesamiento 
del dolor [8]. Por tanto, la unión de este receptor con su ligando transmite señales a la célula para la división y supervivencia de las mismas. La mutación del gen NTRK1 provoca una señalización inadecuada y las neuronas sensoriales mueren por apoptosis [9].

Esta mutación del gen NTRK1 lo que causa es que el receptor TrkA esté truncado debido a que no posee el dominio tirosina quinasa, por lo que el receptor no quedará activo y no se transmitirá la señal de fosforilación y activación de numerosas rutas de crecimiento y supervivencia [10,11]. En concreto se ha visto que conecta con la vía de PI3K, que mediante la activación de Akt, está implicada en supervivencia; con la vía de las MAPK implicada en diferenciación por la activación de ERK, y en la señalización por fosfolípidos, provocando la salida de calcio del retículo endoplasmático hacia el citosol a través de IP3. De este modo, la mutación en el gen NTRK1 termina provocando una alteración en la diferenciación y supervivencia de neuronas sensoriales que hacen que las personas con CIPA no puedan sentir dolor [12].

Con el fin de encontrar posibles dianas terapéuticas se estudia la mutación que surge en el gen NTRK1 y se observa que se encuentra en el brazo largo del cromosoma 1, en concreto en el exón 10. De este modo, se produce una mutación en la secuencia en una guanina $(G)$ y en una adenina (A) y por tanto se codifica para una proteína alterada [13]. Esto conlleva a la pérdida del dominio tirosina quinasa del receptor, de manera que no presenta funcionalidad y no se lleva a cabo la señalización.

Por todo ello, los objetivos que nos planteamos en el presente trabajo son los siguientes: en primer lugar, elaborar un test de posibles portadores, debido a que la enfermedad es autosómica recesiva, con el fin de intentar evitar nuevos casos de la enfermedad, y en segundo lugar reparar la mutación del gen NTRK1 a través de la técnica CRISPR/Cas9.

\section{Materiales y métodos}

\section{Cultivos celulares}

La línea celular de embrión de ratón 3T3L1 procede del aislamiento de un clon de 3T3. Las células sufren una conversión de preadiposa a adiposa mediante una rápida división hasta la confluencia llegando a un estado de inhibición por contacto. Un alto contenido en suero en el medio de cultivo lleva a un rápido grado de acumulación de grasa. Para su cultivo, se utilizó DMEM $+2 \mathrm{mM}$ glutamina $+10 \%$ suero bovino fetal inactivado o RPMI $+2 \mathrm{mM}$ glutamina $+10 \%$ suero bovino fetal inactivado. Los cultivos confluentes se subcultivan sembrando $2-4 \times 10000$ células $/ \mathrm{cm}^{2}$, en frascos de $75 \mathrm{~cm}^{2}$. Se despegan empleando tripsina y EDTA/tripsina y se incuban a $37^{\circ} \mathrm{C}$ y $5 \%$ de $\mathrm{CO}_{2}$. No se puede dejar que el cultivo se llegue a estar completamente confluente y hay que subcultivar cada 3 días.

\section{Plásmidos}

Se utilizaron dos construcciones: una de las construcciones genéticas fue un vector de inserción portador del exón 10 mutado que codifica para el receptor TrkA con el fin de generar la línea de ratones con CIPA. La segunda construcción consistió en un vector de remplazamiento donde se portó el exón 10 silvestre para la recombinación homóloga en la técnica del CRISPR/Cas9.

\section{Electroporación de plásmidos}

El electroporador utilizado fue Electro SquarePorator ECM830 de la empresa Harvard apparatus. El voltaje aplicado fue de $300 \mathrm{~V}$ y la duración del pulso de $500 \mu \mathrm{s}$. Se llevó a cabo la electroporación simple: se añadió al cultivo $10 \mu \mathrm{g}$ de plásmido por $\mathrm{ml}$ de medio.

\section{CRISPR/Cas9}

Para mutagenizar la secuencia con CRISPR y revertir la mutación del exón 10, se buscó la secuencia PAM del gen defectuoso (cercana a la mutación) y se cogió lo que había justo antes hasta 20 nucleótidos. Estos nucleótidos se clonaron en el vector RNA guía. Este vector por tanto contenía, el gen de la caspasa 9, el RNA guía y un cassete promotor de RNA. Si el procedimiento resultó efectivo, mediante la técnica del CRISPR, el RNA guía llevó a la caspasa 9 para cortar el gen defectuoso. Una vez producida la rotura de la doble hebra, la presencia del vector de remplazamiento permitió la edición del gen a voluntad.

\section{Inyección de células y cruzamientos entre ratones adultos}

Para realizar los experimentos in vivo se inyectaron las células embrionarias modificadas por los plásmidos y CRISPR/Cas9 mediante microinyección en blastocisto de ratones. A partir de aquí, se implantaron en el útero de hembras pseudopreñadas y se realizaron los convenientes cruzamientos de quimeras con otros perfiles genotípicos para obtener un linaje de ratones con CIPA y otro de ratones con reversión de la enfermedad. 
PCR

La técnica de PCR se utiliza para amplificar específicamente fragmentos de DNA. En este trabajo se utilizó con el fin de facilitar el clonaje de secuencias de interés mediante la incorporación de dianas de restricción en los extremos 5' de los primers para la realización del CRISPR, así como para facilitar la secuenciación de una región de interés del genoma sin necesidad de fragmentarlo. Se hicieron reacciones de PCR con un volumen final de $10 \mu$ l que contenía: tampón $1 \mathrm{X}, \mathrm{dNTPs}, \mathrm{MgCl}_{2}, \mathrm{DNA}$, oligonucleótidos, Taq polimerasa y $\mathrm{H}_{2} \mathrm{O}$. Las condiciones de la PCR fueron las siguientes: un ciclo de 10 minutos a $95^{\circ} \mathrm{C}$; seguido de 40 ciclos con el esquema $95^{\circ} \mathrm{C}$ durante 30 segundos, $60^{\circ} \mathrm{C}$ durante 30 segundos, $72^{\circ} \mathrm{C}$ durante 30 segundos; y un último ciclo de $10 \mathrm{~min}$ a $72^{\circ} \mathrm{C}$. Transformación en E.Coli

Se descongeló una alícuota de células competentes durante 30' y tras esto, se alicuotaron en tubos eppendorfs previamente enfriados. Se dio un breve pulso de centrifugación a las construcciones y se añadió a las células competentes. Se mezcló bien y posteriormente se incubó 30' en hielo. Para producir el choque térmico, se incubó la mezcla de transformación durante $2^{\prime}$ a $42^{\circ} \mathrm{C}$. Con el fin de expresar los genes de resistencia se añadió $0,9 \mathrm{ml}$ de medio MLB e incubó $30^{\prime}$ a $37^{\circ} \mathrm{C}$. Posteriormente se sedimentaron las bacterias por centrifugación durante 5' a $5.000 \mathrm{rpm}$, se eliminó $750 \mathrm{ul}$ del sobrenadante de manera que sobre el precipitado de bacterias queden todavía unos 200ul de medio de cultivo. Se resuspendió suavemente el sedimento de bacterias en los $200 \mathrm{ul}$ de medio de cultivo remanente. Plaqueamos todo el volumen de bacterias resuspendidas en una placa Petri con medio MLB sólido que contenga $50 \mu \mathrm{g} / \mathrm{ml}$ de ampicilina.

\section{Secuenciación masiva (Illumina)}

Se realizó mediante el kit $A D N$ sin PCR TruSeq. Esta técnica se divide en 4 pasos: primero se prepara la genoteca a través de las fragmentaciones del DNA y unión de linkers 3'y 5'a estos, y se purifica. Después se preparan los clusters y se lleva a cabo una PCR en puente. Posteriormente se lleva a cabo la secuenciación por síntesis que consiste en añadir a la cadena molde de DNA nucleótidos marcados con fluorocromos diferentes cada uno. Por último, cuando ya tenemos la secuencia la comparamos con una wild-type para ver si la muestra tiene mutaciones en el gen y exón que producen la enfermedad (exón 10).

\section{Extracción de proteínas}

Las células embrionarias se sembraron en placas P100 a una densidad de $10^{6}$ células/placa en su medio al $10 \%$ de FBS. Al observarse confluentes, se aspiró el medio de las placas y se lavó con PBS. Se añadió PBS y se recogieron las células en un Falcon de $15 \mathrm{ml}$. Se centrifugó a $1500 \mathrm{rpm}$ durante 5 minutos, se eliminó el sobrenadante y se añadió al sedimento el tampón de lisis, formado por Tritón X-100 al 1\% en tampón base $(50 \mathrm{mM}$ Tris- $\mathrm{HCl}(\mathrm{pH} 7,5) ; 150 \mathrm{mM} \mathrm{NaCl} ; 1 \mathrm{mM}$ EDTA; $1 \mathrm{mM}$ ovanadato de sodio e inhibidores de proteasas comerciales) (Complete EDTA Free de Roche)). Se incubó en rotación durante 30 minutos a $4^{\circ} \mathrm{C}$, para a continuación centrifugarlo a $13.000 \mathrm{rpm}$ durante 10 minutos, también a $4^{\circ} \mathrm{C}$. Una vez centrifugado se recogió el sobrenadante y se determinó el contenido proteico mediante la técnica Bradford (Protein Assay de BioRad). Como estándar se usó una solución de albúmina sérica bovina (Sigma-Aldrich) a una concentración de $1 \mathrm{mg} / \mathrm{ml}$.

\section{Western-blot}

Electroforesis en geles de poliacrilamida en presencia de SDS (SDS-PAGE) (sodium dodecyl sulfate polyacrylamide gel electrophoresis).- Los extractos celulares se calentaron a $96^{\circ} \mathrm{C}$ durante 5 minutos para proceder a su desnaturalización en tampón de Laemmli 5x (SDS 20\%, 20\% 2mercaptoetanol, 40\% glicerol, 0,008\% azul de bromofenol, 0,250 M Tris HCL y agua milQ) y se sometieron a electroforesis en geles de poliacrilamida de una concentración del $8 \%$ en acrilamida. La separación electroforética se llevó a cabo a un potencial eléctrico de entre 90 y 110 voltios en tampón de electroforesis $(25 \mathrm{mM}$ Tris- $\mathrm{HCl}$ (pH8, 3); 192mM Glicina y 0,1\% SDS) según el método Laemmli.

Transferencia.- Una vez conducida la electroforesis, las proteínas se transfirieron a una membrana de PVDF (fluoruro de polivinilideno) mediante la aplicación de una corriente constante de $65 \mathrm{~mA}$ durante 16-18 horas en tampón de transferencia (25 mM Tris- $\mathrm{HCl}(\mathrm{pH} \mathrm{8,3);} 192 \mathrm{mM}$ Glicinag y 20\% metanol).

Inmunodetección con anticuerpos específicos.- Una vez pasado el tiempo de la transferencia se llevó a cabo un bloqueo de la membrana de

PVDF con leche en polvo al 5\% en TTBS (Tris $0,1 \mathrm{mM}, \mathrm{NaCl} 1,5 \mathrm{mM}$ y $0,05 \%$ Tween-20) durante 1 hora a temperatura ambiente, con el fin de bloquear los sitios de unión inespecíficos de la membrana. Pasada esa hora la membrana se incubó con el anticuerpo especifico de la proteína que queríamos detectar. Este anticuerpo se diluyó en TTBS en una proporción de 1:500. El anticuerpo primario se incubó en 1 hora a temperatura ambiente o a $4^{\circ} \mathrm{C}$ durante toda la noche, dependiendo del anticuerpo y la casa comercial de la que procedía. Tras la incubación se lavó la membrana 4 veces durante 10 minutos cada una con TTBS. A continuación, se incubó la membrana con un anticuerpo secundario (Anti-IgG de ratón o de conejo, 
dependiendo del anticuerpo primario), marcado con peroxidasa (HRP), diluido en la misma solución de bloqueo para evitar la unión de inespecíficos. Nuevamente la membrana se lavó 4 veces durante 10 minutos cada una con TTBS. Al finalizar los lavados la membrana se incubó con un reactivo quimioluminiscente como sustrato de la peroxidasa (WesternBright ECL de Advansta). Para ver las proteínas marcadas en la membrana se utilizó un Bio-Rad ChemiDoc Imager.

\section{Citometría de flujo}

Las células embrionarias se sembraron en placas de 6 pocillos a una densidad de 9x10 5 células/pocillo. A las 24 horas se recogió el sobrenadante de las placas en un tubo cónico de $15 \mathrm{ml}$, y se lavó con PBS, recogiéndose en el mismo tubo este PBS y las células que pudiese contener. Las células adheridas a la placa fueron levantadas con $250 \mu \mathrm{l}$ de tripsina durante 5 minutos a $37^{\circ} \mathrm{C}$. Para anular el efecto de la tripsina se adicionó a cada placa $1 \mathrm{ml}$ de su respectivo medio completo (RPMI o DMEN). Posteriormente se centrifugó a $1500 \mathrm{rpm}$ durante 5 minutos a temperatura ambiente. Tras esta centrifugación decantó el sobrenadante y se resuspendió el pellet en $1 \mathrm{ml}$ de medio. Para analizar el ciclo celular se cogió en un tubo $472 \mu \mathrm{l}$ de la suspensión celular, al que se adicionó $3 \mu \mathrm{l}$ de RNAsa a $10 \mathrm{mg} / \mathrm{ml}$ y $25 \mu \mathrm{l}$ de NP40 al $10 \%$, un detergente que permeabiliza la membrana celular. Se dejó incubando 30 minutos a $4^{\circ} \mathrm{C}$, tras los cuales, y antes de pasar las muestras por el contador, se le añadió $25 \mu \mathrm{l}$ de una solución de ioduro de propidio $50 \mu \mathrm{g} / \mathrm{ml}$ final, el cual es un agente intercalante en el DNA.

\section{Resultados}

En primer lugar, nos planteamos analizar posibles mutaciones en el gen NTRK1, el cual es causante de la CIPA, en personas con antecedentes familiares de la enfermedad para saber si son portadores o no con el fin de diseñar una prueba de diagnóstico de portadores a partir del genotipado de los individuos. Esto se realizó mediante la técnica de secuenciación masiva Illumina, tal y como aparece en Material y métodos. Como se observa en la figura 1 , si una persona portadora y una no portadora tienen hijos tendrían un $50 \%$ de probabilidad de que sus hijos fueran también portadores. Pero si dos personas portadoras tuvieran hijos, estos podrían tener la enfermedad en un $25 \%$ de probabilidad. Con este diagnóstico se intentaría dar a conocer a las personas si son portadoras o no de la enfermedad para que en un futuro si quieren tener descendencia lo hagan con la seguridad de que no perjudicarían gravemente la vida de sus hijos.

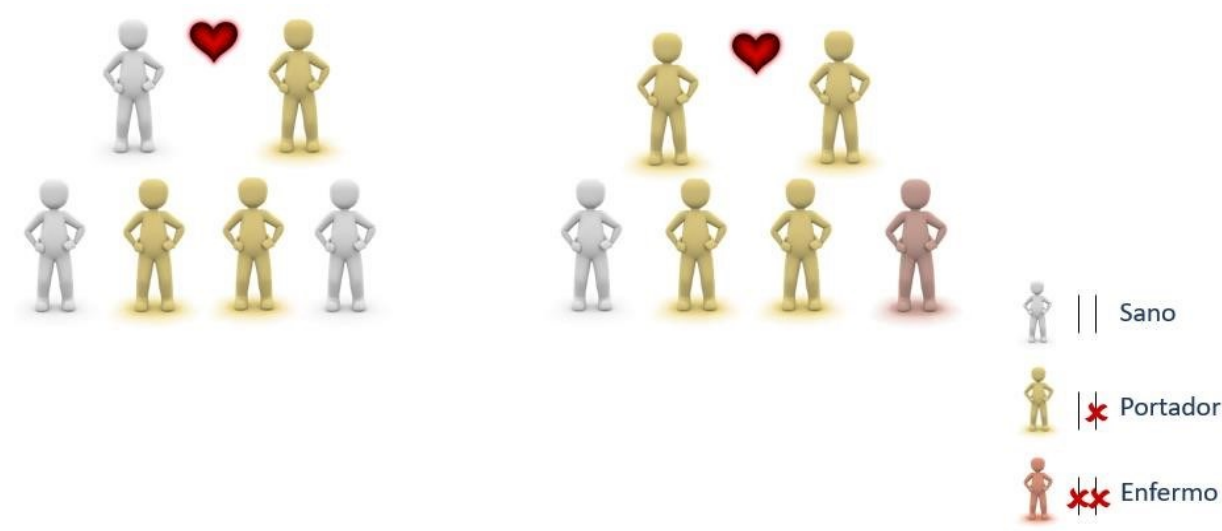

Figura 1. Diagnóstico de portadores. En blanco aparece el individuo sano, en amarillo el individuo portador y en granate el individuo enfermo.

Tras confirmar la existencia de diferentes mutaciones en el gen NTRK1, todas causantes de la enfermedad, quisimos realizar ensayos in vivo para generar una línea estable de ratones enfermos e intentar revertir la mutación. Para ello, realizamos un vector de inserción con una secuencia homóloga al NTRK1 y una secuencia correspondiente al exón 10 mutado. Si el vector se inserta correctamente en el cromosoma, habremos introducido la mutación. Por tanto, extrajimos células embrionarias de ratón sano y electroporamos el vector para poder seleccionar las células modificadas según su resistencia a ampicilina. Con este propósito, fue necesaria la inserción de estas células en un blastocisto de ratón sano, y esto se lo implantamos a una hembra para dar ratones quimeras, ya que partimos de células correspondientes a la recombinación homóloga y células de blastocisto normales. Para obtener un ratón homocigoto recesivo que esté enfermo, cruzamos un ratón quimera con una hembra sana. El resultado fueron ratones heterocigotos para la mutación. Al cruzar estos heterocigotos, conseguimos ver la mutación en homocigosis, es decir, obtuvimos mutantes sólidos enfermos.

Una vez estabilizada la línea de heterocigotos para obtener ratones CIPA, realizamos terapia génica con el fin de remplazar el exón 10 mutado por el wild-type e intentar revertir así la enfermedad en etapa embrionaria. Para comprobar esta hipótesis utilizamos la técnica CRISPR. Para la realización del CRISPR, en primer lugar fue necesario conocer qué mutación exacta portaba cada ratón y para ello, amplificamos el exón mediante PCR y lo clonamos en cepas de E.Coli. Posteriormente realizamos una 
secuenciación del gen como se ha explicado en Material y Métodos. Para mutagenizar una secuencia con CRISPR, buscamos la secuencia PAM del gen defectuoso (cercana a la mutación) y cogimos lo que hay justo antes hasta 20 nucleótidos. Estos nucleótidos los clonamos en el vector RNA guía, amplificando esa región por PCR. Este vector por tanto contuvo, el gen de la caspasa 9, el RNA guía y un cassete promotor de RNA. Para la producción de eventos de recombinación homóloga, en este caso, remplazar el gen mutado por el sano, tuvimos que introducir, junto al sistema CRISPR/Cas9, un DNA homólogo al gen. Por ello construimos un vector de remplazamiento, denominado así porque remplaza lo que hay en el genoma (gen mutado) por lo que hay dentro de los dos trozos del vector (gen sano). Para que esto ocurriera, deben darse dos sobrecruzamientos para que se remplace la pieza del DNA y el cromosoma sea viable.

Una vez hechas ambas construcciones, las electroporamos en células embrionarias de ratón con CIPA. El procedimiento resultó efectivo, y la caspasa 9 cortó el exón. Una vez producida la rotura de la doble hebra, la presencia del vector de remplazamiento permitió la edición del gen a voluntad, es decir, conseguimos remplazar el gen bueno. Esto se confirmó mediante la técnica de PCR tal y como se explica en Material y métodos, y observamos una banda correspondiente al exón 10 wild-type a la altura de su número de pares de bases, que es 100. (Fig2).

Tras esto, y para obtener ratones sanos, implantamos esas células modificadas por CRISPR en un blastocisto de ratón con CIPA, es decir, al revés de lo que hicimos antes para generar el ratón enfermo. Este blastocisto se implanta en una madre enferma, de manera que la descendencia serán ratones quimeras al haber utilizado células embrionarias de un tipo y células de blastocisto de otro tipo. Estos ratones quimera los cruzamos con un ratón enfermo y la descendencia fue heterocigota para la mutación y heterocigota para la reversión de la enfermedad, por lo que mediante cruzamientos de heterocigotos obtuvimos un $75 \%$ ratones sanos, aunque sólo un $25 \%$ homocigotos dominantes.

En el presente estudio hemos demostrado la posibilidad de realizar una terapia génica efectiva a través de la cual poder revertir una enfermedad genética en la etapa embrionaria del ratón. Los resultados preliminares de este trabajo sugieren la posible efectividad del proceso en modelos in vivo. Actualmente se están aprobando estudios con esta técnica en embriones humanos para estudiar la función de diversos genes en etapas tempranas del desarrollo, por lo que no es descabellado pensar que, en un futuro próximo, sea un proyecto plausible para realizar.

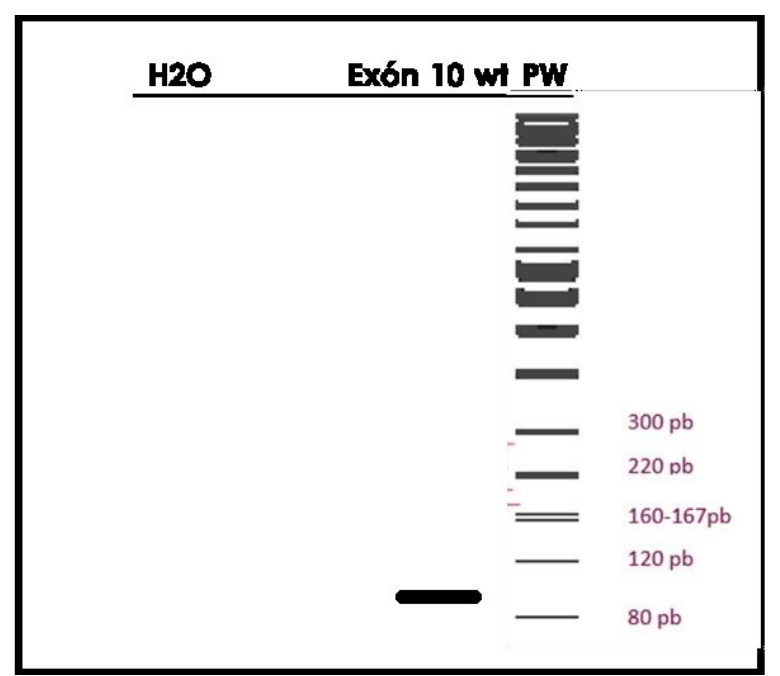

Figura 2. PCR de comprobación del CRISPR. Con primers de amplificación del exón 10 wild-type.

Se utilizó como control negativo el $\mathrm{H} 2 \mathrm{O}$.

Una vez concluida la terapia génica, decidimos realizar unos ensayos de comprobación in vitro para observar la electividad de ésta. Primero de todo quisimos ver la actividad intrínseca del receptor TrkA, para ello, adicionamos a las neuronas el factor de crecimiento nervioso (NGF) y observamos la actividad a lo largo del tiempo, desde el inicio hasta las 24 horas, utilizando el anticuerpo anti-P-TrkA, indicador de la actividad del receptor, por western-blot. Como se puede ver en la figura 3, si la terapia génica es efectiva esperamos observar un aumento de la cantidad de receptor fosforilado a partir de tiempos cercanos como 30 minutos respecto a las células control, que contienen la mutación y por tanto no muestran ningún indicio de fosforilación y actividad del receptor a ningún tiempo.

De este modo, esta terapia ayudaría a devolver la funcionalidad del receptor TrkA, el cual a través de su autofosforilación podrá continuar con la cadena de señalización a través de las diferentes rutas que ayudan en el crecimiento y diferenciación de neuronas nociceptoras, mejorando la ausencia de sensibilidad al dolor y ayudando también a la diferenciación de las neuronas que inervan las glándulas sudoríparas, mejorando a su vez la falta de sudoración en personas con esta enfermedad. 


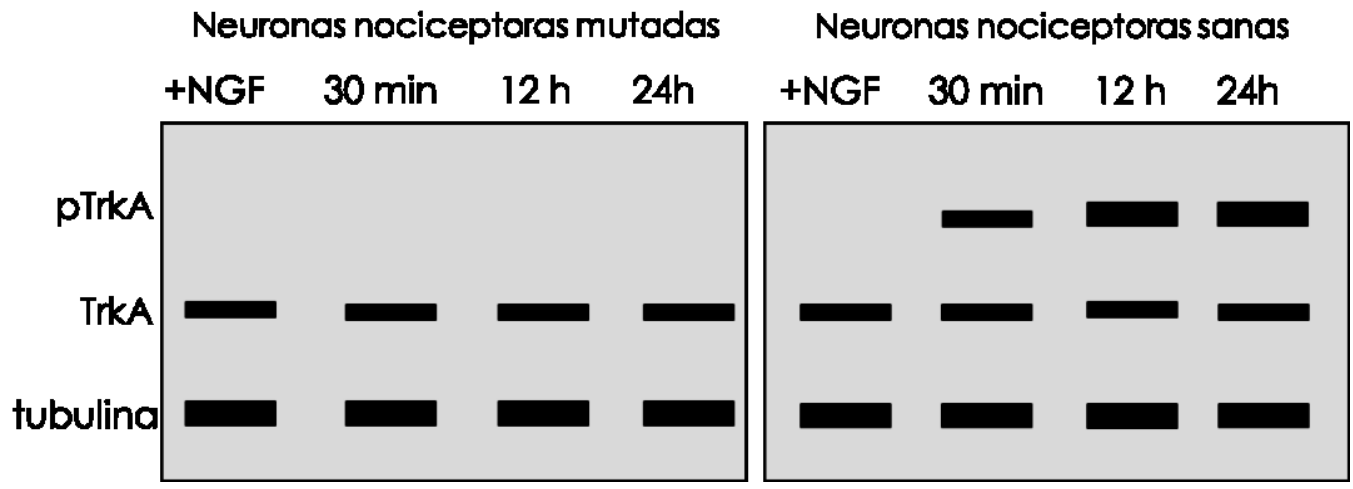

Figura 3. Western-blot de p-TrkA tras la terapia génica. Muestra el aumento de la fosforilación y actividad del receptor TrkA tras la adicción de NGF en neuronas nociceptoras sanas frente a las mutadas (Control).

Posteriormente realizamos otro ensayo para analizar la variación en la apoptosis neuronal tras la terapia génica mediante citometría de flujo con el fin de observar la fragmentación del DNA usando ioduro de propidio como agente intercalante y valorando la fase sub Go del ciclo celular. Como se puede observar en la figura 4, las células control tienen un porcentaje alto de apoptosis, mientras que después de la terapia génica esperamos observar una disminución de la fase Sub Go tras las 24 horas del tratamiento parecida a la de la imagen, lo que nos indica la efectividad de esta terapia. Esta menor apoptosis se podría relacionar con una mayor cantidad de neuronas del dolor activas y funcionales que ayudan a mejorar los síntomas de la enfermedad.

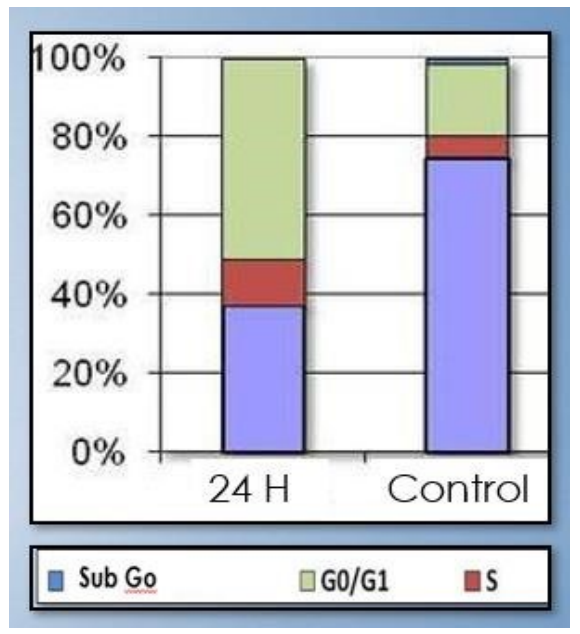

Figura 4. Experimento de citometría de flujo. Se aprecia las distintas fases del ciclo celular en porcentaje tanto en células control como en células tratadas con Crispr a las 24 horas.

Por último, quisimos observar la cantidad de proteína MAP-2c [14], presente en los axones neuronales, antes y después de la terapia génica. Para ello analizamos la cantidad de proteína por western-blot utilizando el anticuerpo anti-MAP-2c. Observando la figura 5, vemos que tanto en las células sanas como en el control aparece esta proteína en torno a $80 \mathrm{KDa}$, aunque en menor medida en las células control, las cuales poseen la mutación. Cuando a las células se les realiza la terapia génica observamos un aumento considerable de la expresión de esta proteína asociada a una mayor diferenciación neuronal y por tanto a una terapia efectiva.

Se ha descrito que esta mayor diferenciación del axón facilita la transmisión de la señal desde las neuronas periféricas hasta el nervio aferente que conecta con la médula espinal, lo que ayuda a la buena señalización por los nervios eferentes para mejorar la reacción a estímulos dolorosos.

Por otra parte, hace poco se ha visto que una proteína del virus del herpes simple, la glicoproteína G, está relacionada con la diferenciación axonal de las neuronas a través de la modificación de la ruta de señalización NGF-TrkA, lo que plantea una posible terapia futura utilizando esta proteína en estos tipos de enfermedad [15]. 


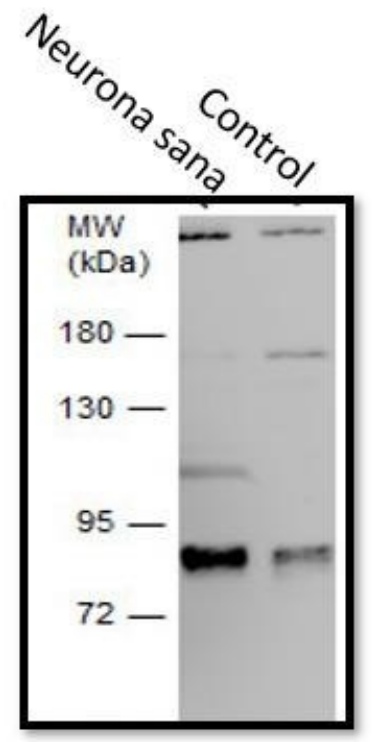

Figura 5 Western-blot de MAP-2c tras la terapia génica. Muestra el aumento de la proteína MAP-2c en las células tratadas con CRISPR frente a las células control.

Todas estas pruebas ayudan a mostrar la efectividad de la posible terapia génica propuesta en el presente trabajo. A día de hoy la terapia génica sigue siendo un tratamiento costoso y poco utilizable en la población, debido principalmente a la alta especificidad que posee, pero con este trabajo ayudamos a mostrar los cuantiosos beneficios que ofrece en esta patología al igual que en muchas otras, ya que no solo ayudan a paliar los síntomas de la enfermedad sino que a través de la modificación genética se podría conseguir la extinción de esta enfermedad y ayudar a mejorar la vida de muchísimas personas en el futuro.

\section{Conclusiones}

Las conclusiones esperables de este estudio teórico serían las siguientes:

La técnica CRISPR consigue revertir de forma eficaz la mutación en el gen NTRK1.

La terapia génica mejora la fosforilación y actividad del receptor TrkA.

La terapia génica consigue una menor apoptosis neuronal.

La terapia génica mejora la diferenciación del axón de la neurona nociceptora.

\section{Bibliografía}

1. Dearborn G. A case of congenital general pure analgesia. J Nerv Ment Dis. 1932; 75: 612.

2. 2-Axelrod, F. and Gold-von Simson, G., 2007. Hereditary sensory and autonomic neuropathies: types II, III, and IV. Orphanet Journal of Rare Diseases, 2(1).

3. Pérez-López LM, Cabrera-González M, Gutiérrez-de la Iglesia D, Ricart S \& Knörr-Gim G. Update Review and Clinical Presentation in Congenital Insensitivity to Pain and Anhidrosis. Case Reports in Pediatrics. 2015; 2015.

4. Indo Y. Congenital Insensitivity to Pain with Anhidrosis. GeneReviews. April 17, 2014; http://www.ncbi.nlm.nih.gov/books/NBK1769/.

5. Hereditary sensory and autonomic neuropathy type 4. Orphanet. November, 2007; http://www.orpha.net/consor/cgi-bin/OC Exp.php?lng=en\&Expert=642.

6. Jagadish, S. and Palled, S., 2014. Congenital Insensitivity to Pain With Anhidrosis. Pediatric Oncall, 11(4).Haga N, Kubota M \& Miwa Z. Epidemiology of hereditary sensory and autonomic neuropathy type IV and V in Japan. Am J Med Genet A. April, 2013; 161A(4):871-874.

7. Franco, M., Melero, C., Sarasola, E., Acebo, P., Luque, A., Calatayud-Baselga, I., GarcíaBarcina, M. and Vilar, M. (2016). Mutations in TrkA Causing Congenital Insensitivity to Pain with Anhidrosis (CIPA) Induce Misfolding, Aggregation, and Mutation-dependent Neurodegeneration by Dysfunction of the Autophagic Flux. Journal of Biological Chemistry, 291(41), pp.21363-21374.

8. Iijima, M. and Haga, N., 2009. Evaluation of nonnociceptive sensation in patients with congenital insensitivity to pain with anhidrosis. Child's Nervous System, 26(8), pp.10851089. 
9. Matrone, C., Marolda, R., Ciafre, S., Ciotti, M., Mercanti, D. and Calissano, P. (2009). Tyrosine kinase nerve growth factor receptor switches from prosurvival to proapoptotic activity via Abetamediated phosphorylation. Proceedings of the National Academy of Sciences, 106(27), pp.1135811363.

10. Arévalo, J. C., Waite, J., Rajagopal, R., Beyna, M., Chen, Z. Y., Lee, F. S., and Chao, M. V. (2006) Cell survival through Trk neurotrophin receptors is differentially regulated by ubiquitination. Neuron 50, 549-559

11. Loeb, D. M., Maragos, J., Martin-Zanca, D., Chao, M. V., Parada, L. F., and Greene, L. A. (1991) The trk proto-oncogene rescues NGF responsiveness in mutant NGFnonresponsive PC12 cell lines. Cell $66,961-966$

12. Rosemberg S, Marie SK, Kliemann S. Congenital insensitivity to pain with anhidrosis (hereditary sensory and autonomic neuropathy type IV). Pediatr Neurol. July, 1994; 11(1):50-56.

13. NTRK1. Genetics Home Reference. May, 2011; http://ghr.nlm.nih.gov/gene/NTRK1.

14. Izant, J. and McIntosh, J. (1980). Microtubule-associated proteins: a monoclonal antibody to MAP2 binds to differentiated neurons. Proceedings of the National Academy of Sciences, 77(8), pp.47414745 .

15. Cabrera, J., Viejo-Borbolla, A., Martinez-Martín, N., Blanco, S., Wandosell, F. and Alcamí, A. (2015). Secreted Herpes Simplex Virus-2 Glycoprotein G Modifies NGF-TrkA Signaling to Attract Free Nerve Endings to the Site of Infection. PLOS Pathogens, 11(1), p.e1004571. 